\title{
Numerical Analysis on Flow Behavior of Molten Iron and Slag in Main Trough of Blast Furnace during Tapping Process
}

\author{
Li Wang, ${ }^{1}$ Chien-Nan Pan, ${ }^{2}$ and Wen-Tung Cheng ${ }^{1}$ \\ ${ }^{1}$ Department of Chemical Engineering, National Chung Hsing University, Taichung, Taiwan \\ ${ }^{2}$ Ceramic Materials Section (T62), New Materials Research \& Development Department, China Steel Corporation, Kaohsiung, Taiwan \\ Correspondence should be addressed to Wen-Tung Cheng; wtcheng@dragon.nchu.edu.tw
}

Received 21 November 2016; Revised 2 February 2017; Accepted 9 February 2017; Published 9 March 2017

Academic Editor: Zhangxin Chen

Copyright (c) $2017 \mathrm{Li}$ Wang et al. This is an open access article distributed under the Creative Commons Attribution License, which permits unrestricted use, distribution, and reproduction in any medium, provided the original work is properly cited.

\begin{abstract}
The three-dimensional model was developed according to number 4 of the main trough of blast furnace at China Steel Co. (CSC $\mathrm{BF} 4)$. The $k-\varepsilon$ equations and volume of fluid (VOF) were used for describing the turbulent flow at the impinging zone of trough, indicating fluids of liquid iron, molten slag, and air in the governing equation, respectively, in this paper. The pressure field and velocity profile were then obtained by the finite volume method (FVM) and the pressure implicit with splitting of operators (PISO), respectively, followed by calculating the wall shear stress through Newton's law of viscosity for validation. Then, the operation conditions and the main trough geometry were numerically examined for the separation efficiency of iron from slag stream. As shown in the results, the molten iron losses associated with the slag can be reduced by increasing the height difference between the slag and iron ports, reducing the tapping rate, and increasing the height of the opening under the skimmer.
\end{abstract}

\section{Introduction}

Liquid phase separation plays a central role in a variety of production technologies [1]. It is important to reduce metal losses associated with the slag in the main trough of the blast furnace $[2,3]$. Insufficient separation gives rise to technological problems in the subsequent processing of hot metal and slag in addition to the losses themselves. The trough, or main iron runner, is made of refractory material and designed to be long enough with suitable skimmer arrangements to obtain good separation of the two liquid phases of iron and slag. Depending on operating conditions, the mixture of molten iron and slag [4], which are continually tapped by the internal pressure of the blast furnace from the blast furnace hearth through a taphole, is separated by the density difference of fluids [5] in the downstream of main trough. As sketched in Figure 1(a), the separation of iron from slag proceeds as the liquids flow down the main trough; consequently, nearly complete separation is expected in the skimmer region. After separation through the skimmer arrangements, the slag is directed to subsequent slag processing facilities, and hot metal is sent to a desulphurization process prior to the steel making process [6].
A few investigations were carried out to study the fluid flow characteristics to enhance the separation efficiency. In the laminar flow regime, where Reynolds number [7] is approximately less than 0.1 , the settling velocity can be expressed by Stoke's law [8] in liquid Al during grain refinement that can be applied for the estimation of settling rate of metal droplets in the liquid slag [9]. For the case of static flow condition, the maximum velocity of droplets is a function of interfacial tension between two liquid phases, density of two liquid phases, and viscosity of continuous phase [10]. In the agitated mixing vessel, the mean diameter of droplets is a function of Weber number [11], viscosity ratio between two phases, and the geometrical factors [12]. An increase in the slag volume leads to a reduction in metal losses because of the greater pressure of the slag column on the pig iron [13]. However, there may exist a certain lower limit of the level when the slag penetration into molten iron [14] is taken into account. For separating two phases concurrent flow in a rectangular channel, the flow behavior was studied by Zhao et al. [15]. They reported that fractional height of upper phase stream (more viscous) is a function of the viscosity ratio and volume fraction of each liquid. Basically, 


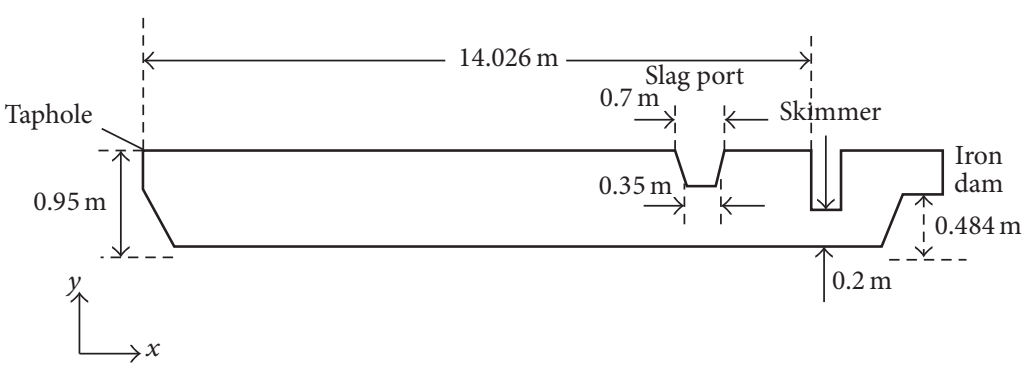

(a)

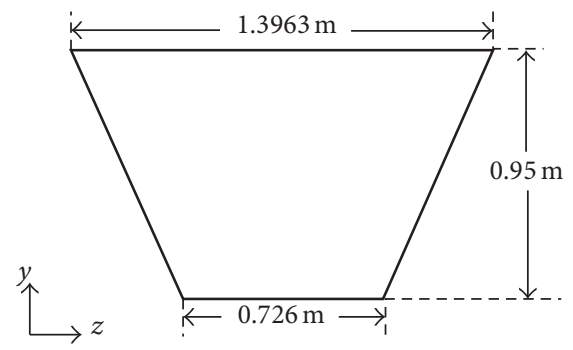

(b)

FIGURE 1: Schematic configuration of main trough: (a) side section and (b) cross section, used in this investigation.

TABLE 1: The physical properties of liquid [21].

\begin{tabular}{lccc}
\hline Property & Temperature $(\mathrm{K})$ & ${\text { Viscosity }\left(\mathrm{kgm}^{-1} \mathrm{~s}^{-1}\right)}$ & Density $\left(\mathrm{kgm}^{-3}\right)$ \\
\hline \multirow{2}{*}{ Iron } & 1773 & 0.00715 & 7000 \\
& 1823 & 0.007 & 6500 \\
Slag & 1773 & 0.2 & 2600 \\
& 1823 & 0.18 & 2000 \\
\hline
\end{tabular}

this mechanism behavior will be applicable for the blast furnace trough system; accordingly, the interface level will be determined by the competition between gravitational force balance [16] in the trough and viscous force balance between two phases [17].

In the mold of a continuous caster [18], which is similar to blast furnace trough system, the slag entrainment mechanism has been studied. Feldbauer et al. [19] reported that there exists a critical velocity of molten steel necessary to cause slag entrainment and the velocity is a function of physical properties of fluids such as density, viscosity, and interfacial tension. Kim et al. [20] carried out a series of experiments, including changing the dimensions of the trough and various process variables such as total discharge rate from the furnace, volume fraction of each liquid, and viscosity of oil. Based on the results, the separation mechanism and the effect of each variable on the separation efficiency were identified. Furthermore, Luomala et al. [21] modeled fluid flows in the main trough of blast furnace to analyze the effects of the height difference between the slag and iron ports, the height of the bath level, and the height of the opening under the skimmer on the amount of entrained slag. As resulting from the calculation, the bigger the height of the iron layer above the opening under the skimmer, the smaller the amount of entrained slag.

As viewed from the above, the active modulation and control of the liquid phase separation are still challenge for high-temperature mixtures of iron and slag. In the present study, we aim to numerically analyze the separation efficiency of melt iron and slag in the main trough of blast furnace through the computer fluid dynamics (CFD) with the different operating conditions and main trough geometry. From the methodology point of view, an effective route to manipulate the separation of iron and slag in main trough of blast furnace depends on the geometry of trough, tapping rate, and the ratio of iron to slag in the fluids. At the present, according to our best knowledge, the computational fluid dynamics are firstly to systematically the parameters of main trough for studying the separation efficiency of molten iron from slag of blast furnace during tapping process.

\section{Problem Formulation}

2.1. Physical Model. The main trough of blast furnace number 4 at China Steel Co (CSC BF4) with 7200 tons/day of production capacity was modeled for the three-dimensional computational fluid dynamics (CFD) to investigate the separation efficiency of molten iron and slag in this work. As expressed in the Cartesian $(x, y, z)$ system, Figure 1 shows the side view and cross section of trough with the dimension in the unit of meter. The molten iron and slag were tapped into the main trough from the taphole tilted by the angle of 10 degrees and drained out at the slag port and iron dam, respectively. In the upstream portion of the trough, a considerable amount of turbulence of the bulk molten iron and slag arises from the kinetic energy of the falling stream. It is clear that the turbulent energy is variable and depends on the discharge rate of liquid, increasing with enlarging the taphole size. The slag separated from iron while traveling along the trough equipped with the skimmer due to the density difference and flowed out via slag port. Additionally, the thermal heat transfer was considered for forced convection induced by the difference temperature of tapping stream and the vertical wall of trough as well as natural convection due to the gravity force in the normal direction. In addition, according to literature [22], Table 1 lists the physical properties of liquid in this study.

2.2. Conservation Equation. For conservation equations, the following assumptions were made: (1) the chemical reaction [23], thermal radiation [24], and Marangoni effect [25] are ignorable; (2) air, iron, and slag are incompressible fluid [26]; (3) the interface of iron-slag in the taphole was kept as a 
horizontal surface, and slag was floated on iron because of lighter density; (4) the determination of the size of liquid droplets in another immiscible liquid was not done; and (5) the main trough of blast furnace was unattacked. Accordingly, the equations of continuity and motion were expressed in the rectangular coordinates [27] as

$$
\begin{aligned}
\frac{\partial}{\partial x}\left(\rho_{\text {mix }} u\right)+\frac{\partial}{\partial y}\left(\rho_{\text {mix }} v\right)+\frac{\partial}{\partial z}\left(\rho_{\text {mix }} w\right)=0 & \\
\rho_{\text {mix }} & \left(\frac{\partial u}{\partial t}+u \frac{\partial u}{\partial x}+v \frac{\partial u}{\partial y}+w \frac{\partial u}{\partial z}\right) \\
= & -\frac{\partial P}{\partial x}+\frac{\partial}{\partial x}\left(\mu_{\mathrm{eff}} \frac{\partial u}{\partial x}\right)+\frac{\partial}{\partial y}\left(\mu_{\mathrm{eff}} \frac{\partial u}{\partial y}\right) \\
& +\frac{\partial}{\partial z}\left(\mu_{\mathrm{eff}} \frac{\partial u}{\partial z}\right) ; \\
\rho_{\mathrm{mix}} & \left(\frac{\partial v}{\partial t}+u \frac{\partial v}{\partial x}+v \frac{\partial v}{\partial y}+w \frac{\partial v}{\partial z}\right) \\
= & -\frac{\partial P}{\partial y}+\frac{\partial}{\partial x}\left(\mu_{\mathrm{eff}} \frac{\partial v}{\partial x}\right)+\frac{\partial}{\partial y}\left(\mu_{\mathrm{eff}} \frac{\partial v}{\partial y}\right) \\
& +\frac{\partial}{\partial z}\left(\mu_{\mathrm{eff}} \frac{\partial v}{\partial z}\right)+\rho_{\mathrm{mix}} g \\
& +\frac{\partial}{\partial z}\left(\mu_{\mathrm{eff}} \frac{\partial w}{\partial z}\right) . \\
\rho_{\text {mix }} & \left.\frac{\partial w}{\partial t}+u \frac{\partial w}{\partial x}+v \frac{\partial w}{\partial y}+w \frac{\partial w}{\partial z}\right) \\
& -\frac{\partial}{\partial x}\left(\mu_{\mathrm{eff}} \frac{\partial w}{\partial x}\right)+\frac{\partial}{\partial y}\left(\mu_{\mathrm{eff}} \frac{\partial w}{\partial y}\right)
\end{aligned}
$$

In (1), the mean density is

$$
\rho_{\text {mix }}=\sum_{q=1}^{3} \alpha_{q} \rho_{q}
$$

with $\sum_{q=1}^{3} \alpha_{q}=1$, where $\alpha$ indicates the fraction of volume and $q$ is subscript noticing phase number, $t$ is the time, $g$ indicates the gravity force, and $\rho_{q}$ is the density of individual phase, which should be associated with the volume fraction equation [28],

$$
\frac{\partial}{\partial t}\left(\alpha_{q} \rho_{q}\right)+\vec{\nabla} \cdot\left(\alpha_{q} \rho_{q} \vec{u}\right)=0
$$

where $\vec{\nabla}$ is vector differential operator, also called nabla operator [29], and $\vec{u}$ expresses the velocity vector including the velocities components of $u, v$, and $w$, responding to $x$, $y$, and $z$ direction, respectively, and the effective viscosity is $\mu_{\text {eff }}=\mu_{\text {mix }}+\mu_{t}$, where mean viscosity was defined by

$$
\mu_{\text {mix }}=\sum_{q=1}^{3} \alpha_{q} \mu_{q}
$$

where $\mu$ is the viscosities of air, slag, and iron, respectively, denoted by phase number, $q$, and the turbulent viscosity is $\mu_{t}=C_{\mu} \rho k^{2} / \varepsilon$, where the turbulent kinetic energy, $k$, and energy dissipation rate, $\varepsilon$, were obtained by solving the $k-\varepsilon$ equations [30],

$$
\begin{aligned}
\rho_{\text {mix }} & \left(\frac{\partial k}{\partial t}+u \frac{\partial k}{\partial x}+v \frac{\partial k}{\partial y}+w \frac{\partial k}{\partial z}\right) \\
= & \frac{\partial}{\partial x}\left(\mu_{\mathrm{eff}} \frac{\partial k}{\partial x}\right)+\frac{\partial}{\partial y}\left(\mu_{\mathrm{eff}} \frac{\partial k}{\partial y}\right)+\frac{\partial}{\partial z}\left(\mu_{\mathrm{eff}} \frac{\partial k}{\partial z}\right) \\
& +G_{k}+G_{b}-\rho_{\mathrm{mix}} \varepsilon \\
\rho_{\operatorname{mix}} & \left(\frac{\partial \varepsilon}{\partial t}+u \frac{\partial \varepsilon}{\partial x}+v \frac{\partial \varepsilon}{\partial y}+w \frac{\partial \varepsilon}{\partial z}\right) \\
= & \frac{\partial}{\partial x}\left[\left(\mu_{\text {mix }}+\frac{\mu_{t}}{1.3}\right) \frac{\partial \varepsilon}{\partial x}\right] \\
& +\frac{\partial}{\partial y}\left[\left(\mu_{\mathrm{mix}}+\frac{\mu_{t}}{1.3}\right) \frac{\partial \varepsilon}{\partial y}\right] \\
& +\frac{\partial}{\partial z}\left[\left(\mu_{\mathrm{mix}}+\frac{\mu_{t}}{1.3}\right) \frac{\partial \varepsilon}{\partial z}\right]+1.44 \frac{\varepsilon}{k}-1.92 \rho \frac{\varepsilon^{2}}{k}
\end{aligned}
$$

where the turbulence kinetic energy due to velocity gradient [31] is $G_{k}=-\rho_{\text {mix }} \overline{u^{\prime} v^{\prime}}(\partial v / \partial z)$ and due to the mean velocity fluctuation is $\overline{u^{\prime} v^{\prime}}$, and the turbulence kinetic energy for thermal buoyancy [32] is $G_{b}=\beta g\left(\mu_{t} / 0.85\right)(\partial T / \partial \mathrm{z})$, with thermal expansion coefficient, $\beta$, subject to the momentum equation and temperature, $T$.

In addition, conservation of energy is written as

$$
\begin{gathered}
\rho_{\text {mix }} C_{p, \text { mix }}\left(\frac{\partial T}{\partial t}+u \frac{\partial T}{\partial x}+v \frac{\partial T}{\partial y}+w \frac{\partial T}{\partial z}\right) \\
=\frac{\partial}{\partial x}\left(\Phi_{\operatorname{mix}} \frac{\partial T}{\partial x}\right)+\frac{\partial}{\partial y}\left(\Phi_{\operatorname{mix}} \frac{\partial T}{\partial y}\right) \\
+\frac{\partial}{\partial z}\left(\Phi_{\operatorname{mix}} \frac{\partial T}{\partial z}\right),
\end{gathered}
$$

where the mean specific heat, $C_{p \text {,mix }}$, and mean heat conductivity, $\Phi_{\text {mix }}$, were expressed in terms of volume of fluid as

$$
\begin{gathered}
C_{p, \text { mix }}=\sum_{q=1}^{3} \alpha_{q} C_{p, q}, \\
\Phi_{\text {mix }}=\sum_{q=1}^{3} \alpha_{q} \Phi_{q},
\end{gathered}
$$

where $C_{p, q}$ and $\Phi_{q}$ are the specific heat and thermal conductivity of individual fluid, respectively.

2.3. The Initial Condition. Under the conditions of large capacity of blast furnace equipped with multiple tapholes, interchanging tapping is done at time intervals for batch production of main trough. In the final discharging stage at first 


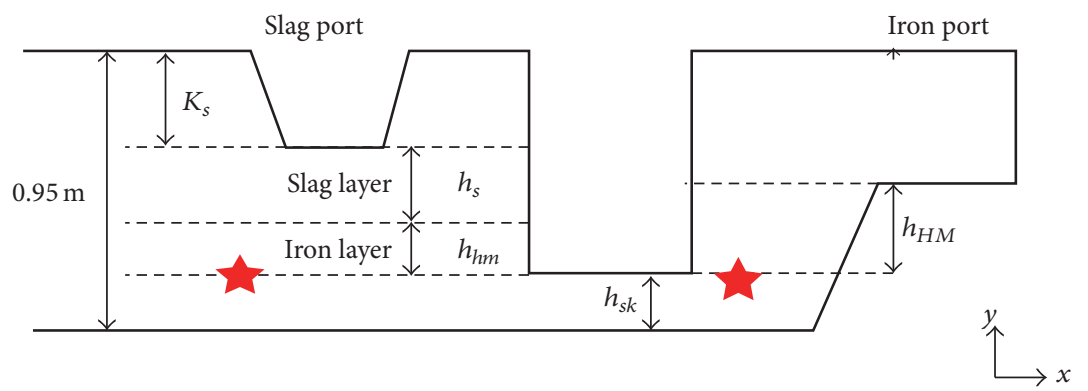

FIgURE 2: The initial level of molten slag and iron in main trough before tapping, as $t=0$.

batch, the molten iron and slag cannot flow because the liquid levels are not over the iron dam and slag port, respectively, stagnating in the main trough. Figure 2 schemes the initial level of melt slag and iron in the main trough before next tapping, as $t=0$. Since the pressure on both sides of skimmer, as denoted by the red start, is virtually the same, the layer thicknesses of melt slag and iron are $h_{s}=0.168 \mathrm{~m}$ and $h_{h m}=$ $0.232 \mathrm{~m}$ at the initial stage, which are calculated by (8) and (9), respectively [21].

$$
\begin{aligned}
h_{s} & =\left(K_{s y}-K_{h m}\right)-h_{h m} \\
h_{h m} & =\frac{\rho_{h m} \cdot h_{H M}-\rho_{s}\left(K_{s y}-K_{s}\right)}{\rho_{h m}-\rho_{s}} .
\end{aligned}
$$

The nomenclatures used in (8) and (9) are, respectively, illustrated in the symbol list.

2.4. The Boundary Conditions. To simulate that the tapping stream is injected into the main trough from the taphole of blast furnace hearth and solve (1) to (6), the boundary conditions were specified as (1) the pressure which is contact surface under the atmosphere of $1 \mathrm{~atm}$; (2) the no-slip conditions were imposed, and the wall temperature is set as $1773 \mathrm{~K}$; (3) the rate ratio of molten iron to slag in the taphole was $3: 1 ;(4)$ the velocity of iron at the inlet was expressed by $\vec{u}_{\text {iron }}=6 \cdot \cos 10^{\circ} \vec{i}+6 \cdot \sin 10^{\circ} \vec{j}+0 \vec{k}$, with, $\vec{i}, \vec{j}$, and $\vec{k}$ being the unit vector at the $x, y$, and $z$ directions, respectively, whose turbulence intensity is $3.07 \%$. (5) The velocity of slag at the inlet was expressed by $\vec{u}_{\text {slag }}=2 \cdot \cos 10^{\circ} \vec{i}+2 \cdot \sin 10^{\circ} \vec{j}+$ $0 \vec{k}$, whose turbulence intensity is $6.63 \%$, and the liquid temperature at the inlet is $1823 \mathrm{~K}$. The turbulence intensities were calculated by the formula from the documentation [33]. The velocities of molten iron and slag at the inlet were calculated from the actual tapping rate, which was assumed to be 5 tons/min of molten iron on average.

\section{Numerical Solution}

The Eulerian model for a multiphase flow as implemented in the Fluent 6.2 [33] was used to solve conservation equations (1) (6) that were separated using the finite volume technique in the computational domain ranging from the inlet at the taphole to the outlet at slap port and iron dam, respectively, as

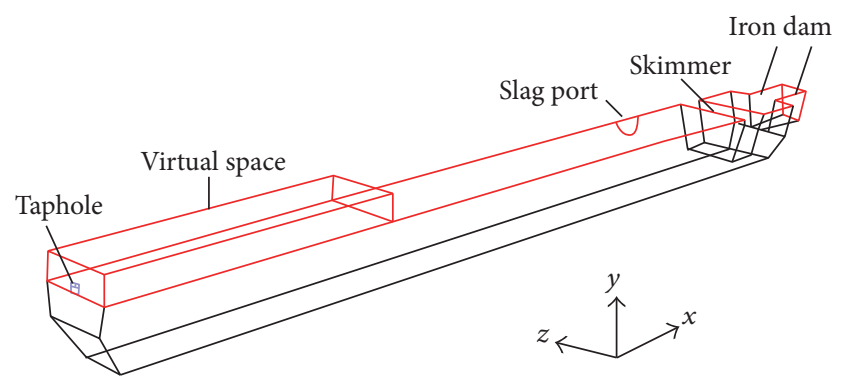

FIGURE 3: Three-dimensional computational domain used in this study.

sketched in Figure 1, associated with the initial and boundary conditions. Pressure-Implicit Split-Operator (PISO) [34] was applied in pressure-velocity coupling in the segregated solver to adjust the velocity fields by correcting the pressure field. The second upwind scheme [35] was chosen to separate the convection term of governing equation. Figures 3 and 4 demonstrate the computational domain and grid of blast furnace main trough, respectively. In Figure 3, the virtual space was added to aid for simulating the actual tapping stream from the taphole to the main trough of blast furnace.

The resulting numerical solution was used to calculate the wall shear stress $\left(\tau_{w}\right)$ and separation efficiency $(\eta)$ of molten iron from slag at slag port by (10) and (11), respectively, at steady state.

$$
\tau_{w}=\mu_{\mathrm{eff}} \frac{\partial \vec{u}}{\partial \vec{n}},
$$

where $\vec{n}$ is the normal vector.

$$
\eta(\%)=\left(1-\frac{\dot{m}_{\text {out }}}{\dot{m}_{\text {in }}}\right) \times 100 \%,
$$

where the mass flow rate of melted iron at the slag port, $\dot{m}_{\text {out }}$, was obtained by

$$
\dot{m}_{\text {out }}=\int \rho_{\text {iron }} \cdot \vec{u}_{\text {out }} d A_{\text {out }} ;
$$

and the mass flow rate of iron at the taphole, $\dot{m}_{\text {in }}$, was calculated by

$$
\dot{m}_{\text {in }}=\int \rho_{\text {iron }} \cdot \vec{u}_{\text {in }} d A_{\text {in }} .
$$




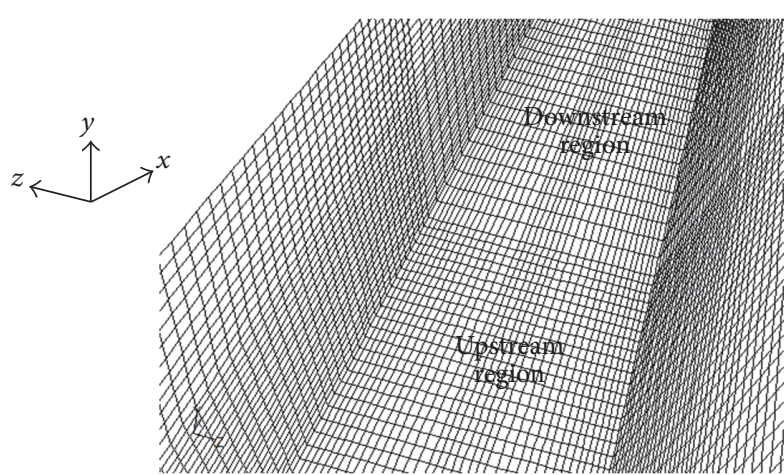

(a)

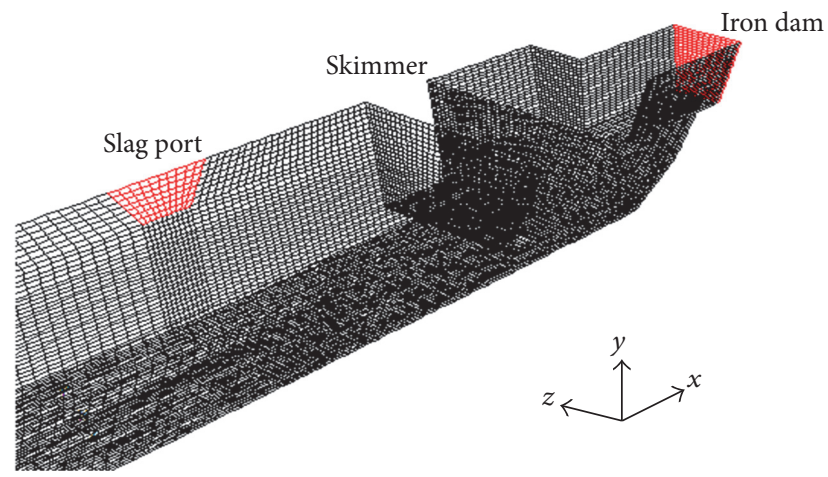

(b)

Figure 4: Computational grid: (a) internal area including upstream and downstream regions and (b) close to outlet at slag port and iron dam of main trough.

In (10) and (11), $A_{\text {out }}$ and $A_{\text {in }}$ express the cross area at slag port and inlet, respectively. During computational period, the steady state was determined by the criteria, $\Delta$, which is defined as

$$
\Delta=\frac{\dot{m}_{\text {in total }}-\dot{m}_{\text {out total }}}{\dot{m}_{\text {in total }}} \times 100 \leq 5 \%,
$$

where $\dot{m}_{\text {in total }}$ and $\dot{m}_{\text {out total }}$ are the total mass flow rates at inlet and outlet, respectively, including the mass flow rates of molten iron and slag.

\section{Results and Discussion}

4.1. Validation. For the validation of computational grid, the wall shear stress profile in the $x$-direction at the position of $y=0.4 \mathrm{~m}$ in the main trough affected by the mesh number was presented in Figure 5. As shown in the figure, the maximum wall shear stress at the distance from the taphole being about $3 \mathrm{~m}$ would be nearly a constant value when the mesh number is larger than 276705. Therefore, for the accuracy of the solution and saving computational time, the case $\mathrm{C}$ of mesh number was considered in this study.

Figure 6 shows the effect of natural convection on the velocity vector in the cross section at the buffer region of main trough. It was clearly seen that swirl flows of melt slag and iron occur in close to wall of main trough due to buoyancy

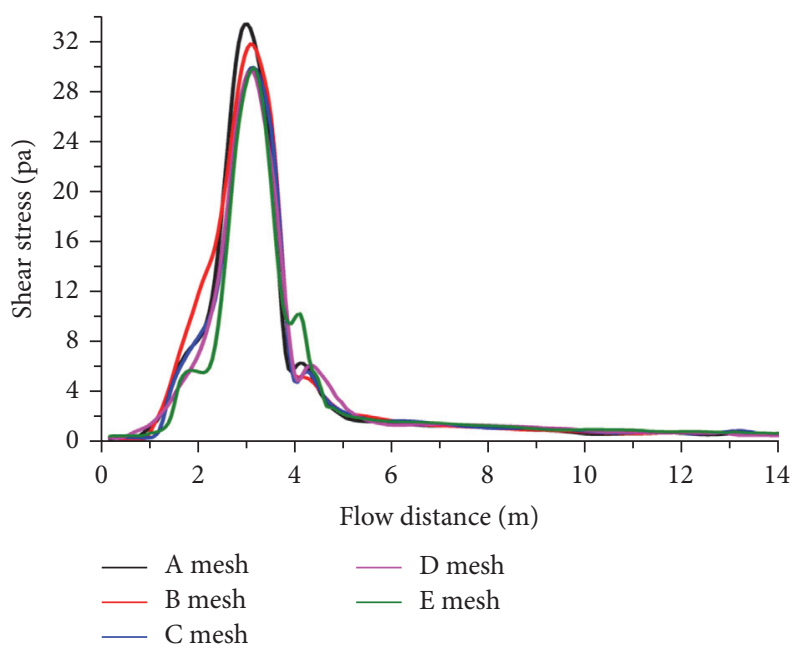

FIGURE 5: Effect of the computational grid on wall shear stress in the direction of fluid flow at the high of $0.4 \mathrm{~m}$ in the main trough.

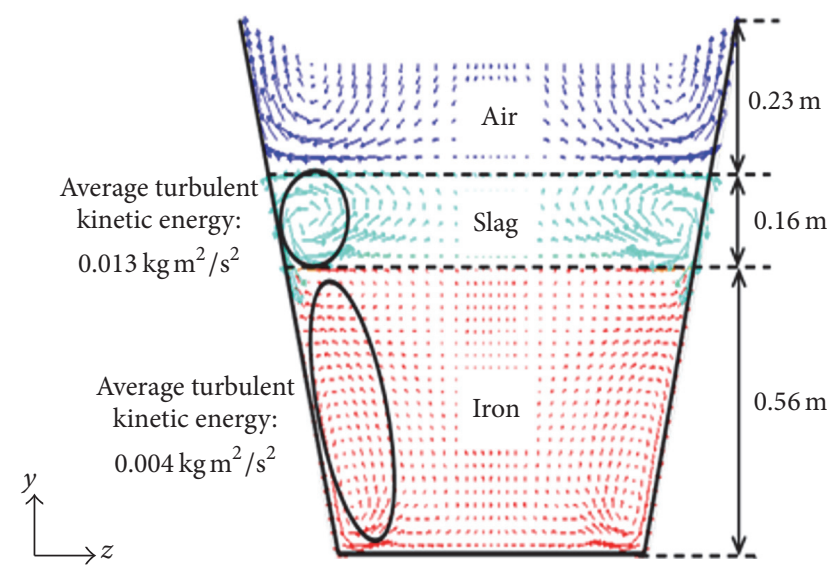

FIGURE 6: It shows the effect of natural convection on the velocity vector in the cross section at buffer region of main trough.

dominated by the density of fluid as function of temperature, inducing the wall shear stress on the vertical wall in the downstream of main trough, as displayed in Figure 7.

In addition, it was found that the loss rate of molten iron from slag port varying with the flow rate of tapping stream obtained by numerical results is similar to the experimental result, whose water and oil were used to simulate the melted iron and slag, respectively, from literature [20], as shown in Figure 8. Therefore, the numerical model of this study could be applied for the sensitivity study on the separation efficiency of molten iron and slag by the different operation conditions and the geometry of blast furnace trough.

4.2. Effect of Discharge Rate. The discharge rates of the molten iron and slag would be significantly changed as the cast proceeds. This is mainly because the size of taphole was enlarged during tapping due to erosion of the refractory material. Figure 9 demonstrates the path line of molten iron and slag in terms of the density phase to be affected by the 

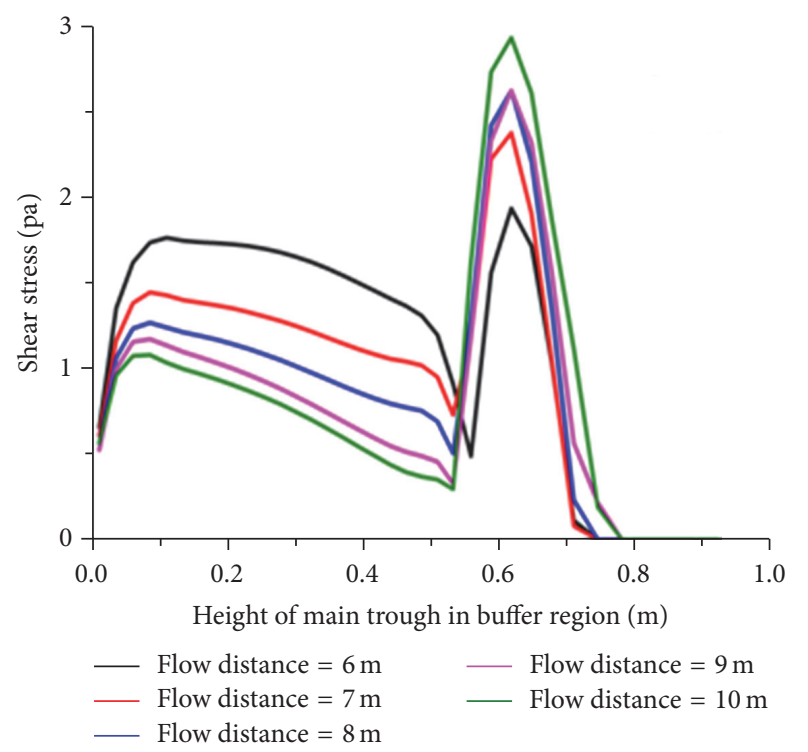

FIGURE 7: The wall shear stress distribution in the vertical direction in the downstream of trough.

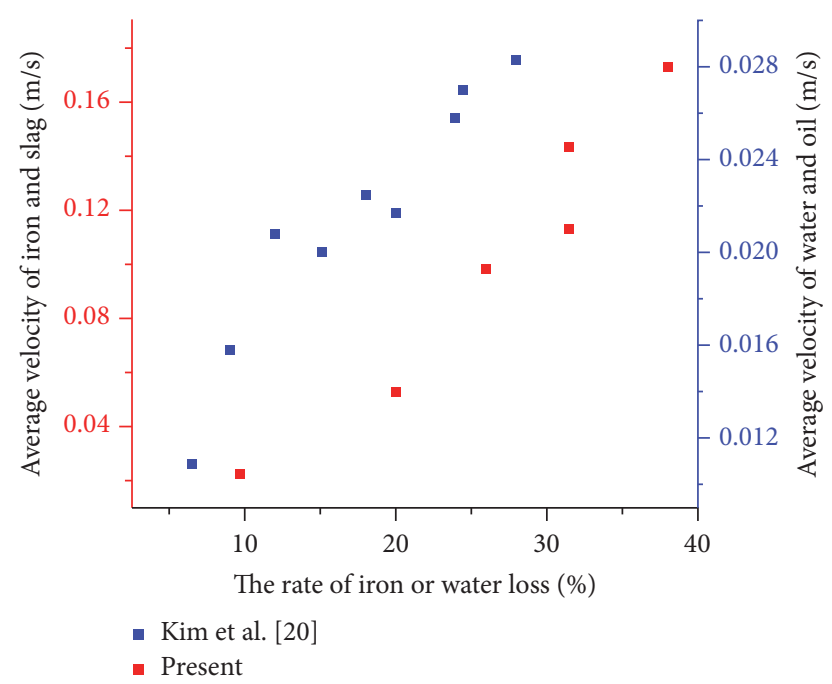

Figure 8: The lost ratio of iron and water from the slag port of trough varying with the velocities of molten slag/iron and oil/water obtained from (a) present study and (b) Kim et al. [20], respectively.

velocity of tapping stream near the slag port. As seen from the figure, the amount of iron trapped in the slag stream was increased with the velocity of tapping stream. When the metal droplets are under the influence of the bulk flow motion, their settling will be hindered and retention time would be shorted in the downstream of main trough. Therefore, the flow velocity of the liquids is an important factor to determine the separation efficiency of molten iron and slag, meaning that the enlarged tapping stream rate would increase the losses of molten iron at slag port.

4.3. Effect of Main Trough Geometry. The effect of main trough geometry on separation efficiency was studied by
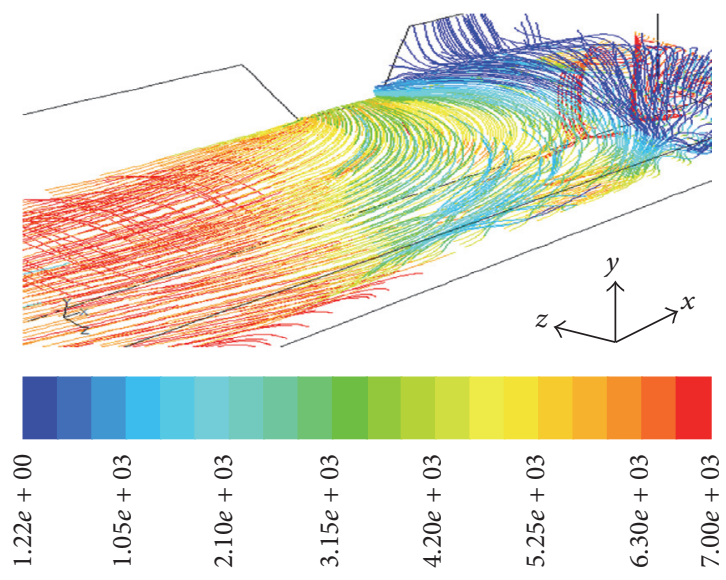

(a)
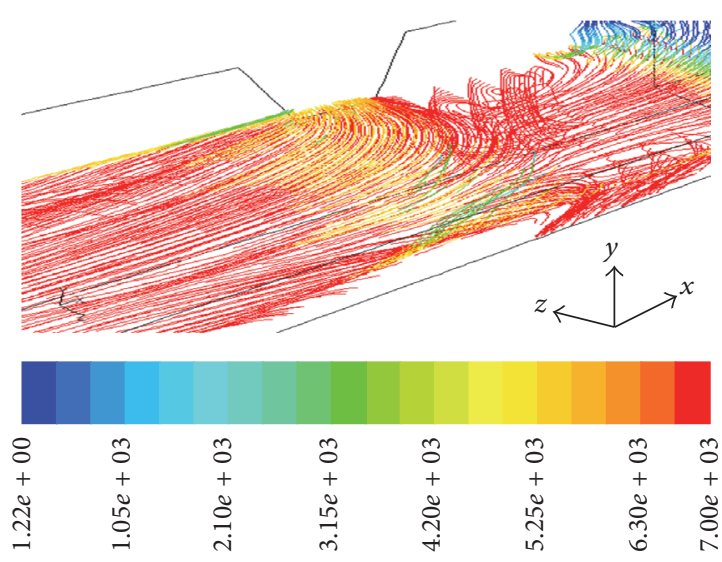

(b)
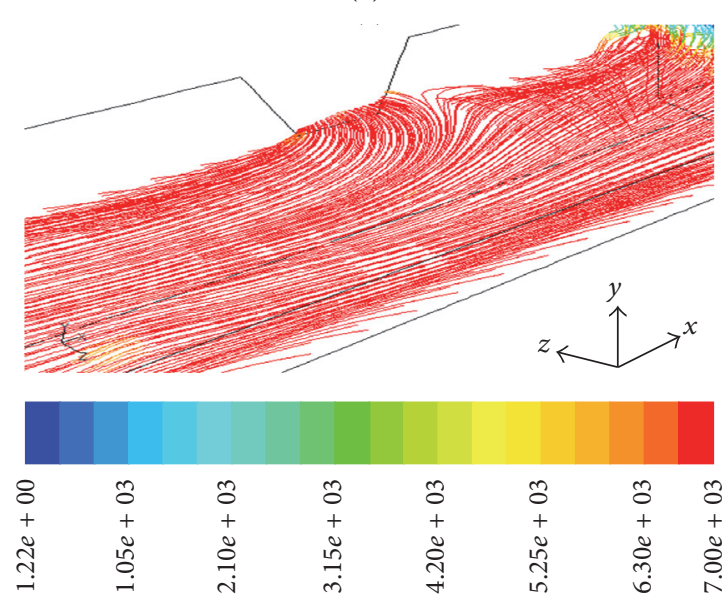

(c)

FIgURE 9: The path line of molten iron and slag in terms of the density in the tapping stream with the velocities of (a) 0.0225; (b) 0.0975 ; and (c) $0.1725(\mathrm{~m} / \mathrm{s})$, respectively, near the slag port of trough.

changing the high difference between iron dam and slag port and the depth of skimmer. The volume rate in main trough is considered for the geometry effect. In the main trough, the interface level of molten iron and slag was influenced by the flow velocity in each stream and the fluid dynamic balance between two phases of fluids, respectively. The molten iron 

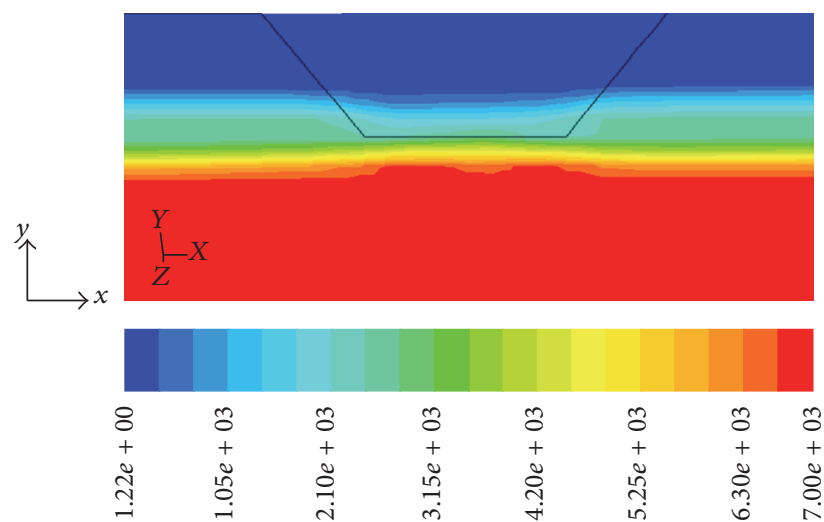

(a)
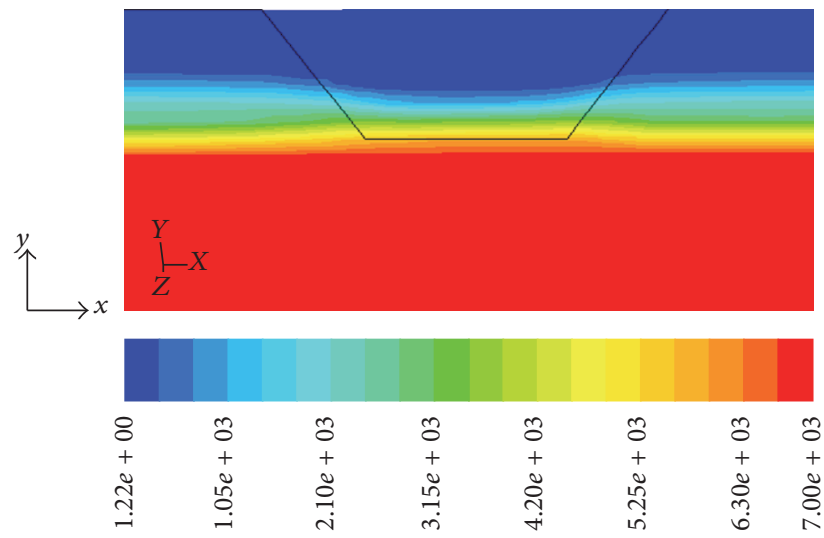

(b)

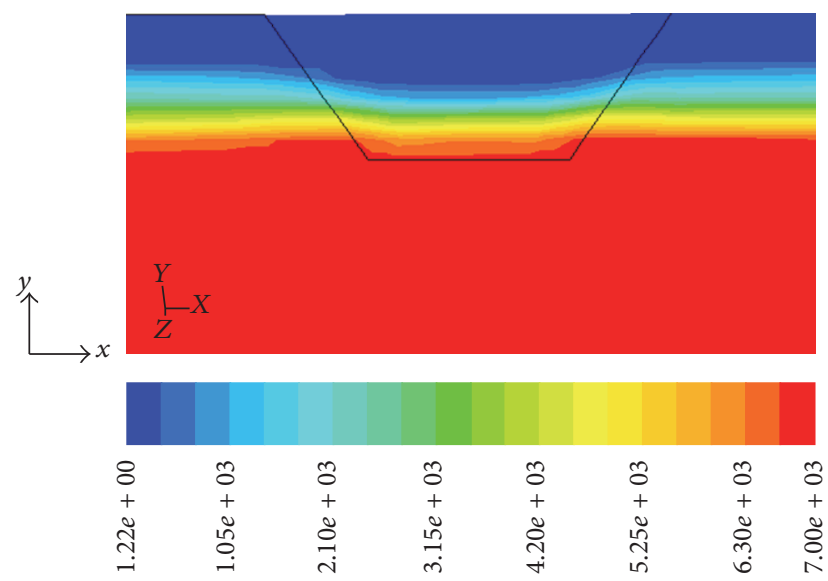

(c)

FIGURE 10: The molten iron lost in terms of the density phase at the slag port varying with the high difference of slag port to iron dam in the main trough of blast furnace: (a) $0.2 \mathrm{~m}$; (b) $0.1 \mathrm{~m}$; and (c) $0.05 \mathrm{~m}$.

lost from the slag port will be increased when the high difference between the slag port and iron dam is reduced, as shown in Figure 10, resulting from elevating the liquid level of molten iron in the downstream of main trough. Figure 11 displays that the separation efficiency of molten iron from the slag could be $100 \%$ when the height difference between iron dam and slag port is $0.2 \mathrm{~m}$ in this work. In contrast, when

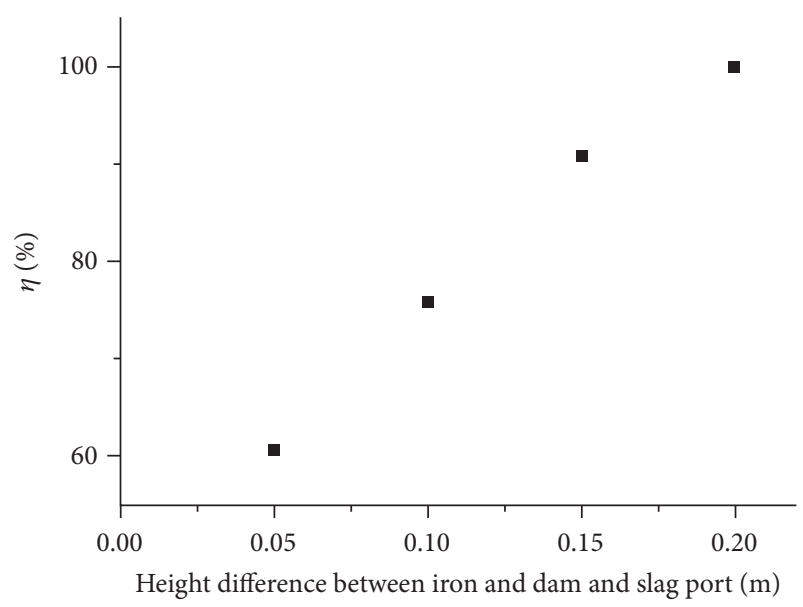

FIGURE 11: Separation efficiency of molten iron from slag phase varying with the height difference between iron dam and slag port.

the height of iron dam is increased, the interface level will be elevated in the trough, resulting in the molten iron flowing into the slag port easily.

In addition, as sketched in Figure 1(a), the depth of skimmer is deeply leading to the interface level being risen and enhances the molted iron flowing into slag port. Figure 12 shows that the depth of skimmer is close to the bottom of the trough, where the turbulent kinetic energy is larger, strongly induced by the slag circulation flow in the upstream to mix the molten iron. This means that the more the skimmer is deeper to the trough bottom, the worst the separation efficiency of molten iron from slag at the slag port is. Figure 13 presents that the separation efficiency can be improved by $5.7 \%$, while the depth of skimmer to the main trough bottom of blast furnace was changed from 0.1 to $0.3 \mathrm{~m}$ in the this study

\section{Conclusion}

In this study, the full three-dimensional computational fluid dynamics composed from finite volume method and volume fraction equation in the present of natural thermal convection have been successfully developed to analyze the separation efficiency of molten iron and slag in the main trough of blast furnace. As resulting from the sensitivity analysis, particularly, it was evident that the lost rate of molten iron from the slag port is linearly increasing with increasing the velocity of tapping stream due to insufficient retention time of molten iron in the buffer region of main trough, and when the high difference between slag port and iron dam is less than $0.2 \mathrm{~m}$, the separation efficiency of molten iron from slag could be more and more worse, resulting from elevating the liquid level of molten iron in the downstream of the trough. This suggests that the precise control of the high difference between iron dam and slag port is the priority of importance for maintaining the effectiveness of the slag and metal separation in the main trough of blast furnace during tapping process. 


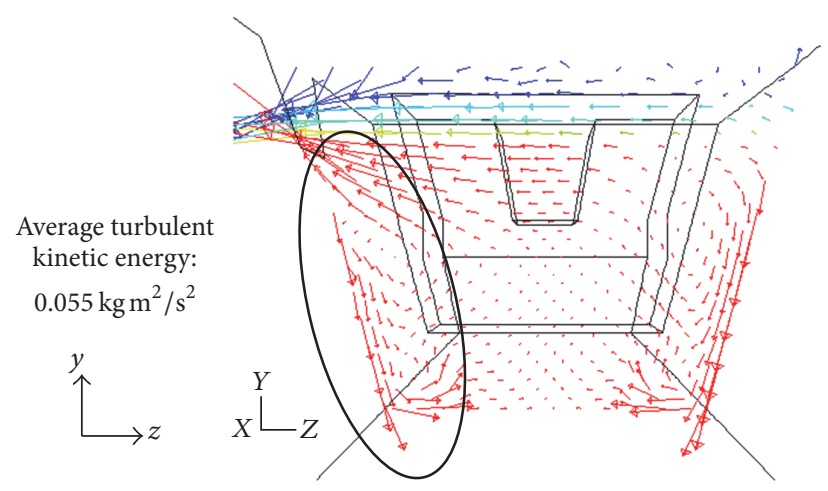

(a)

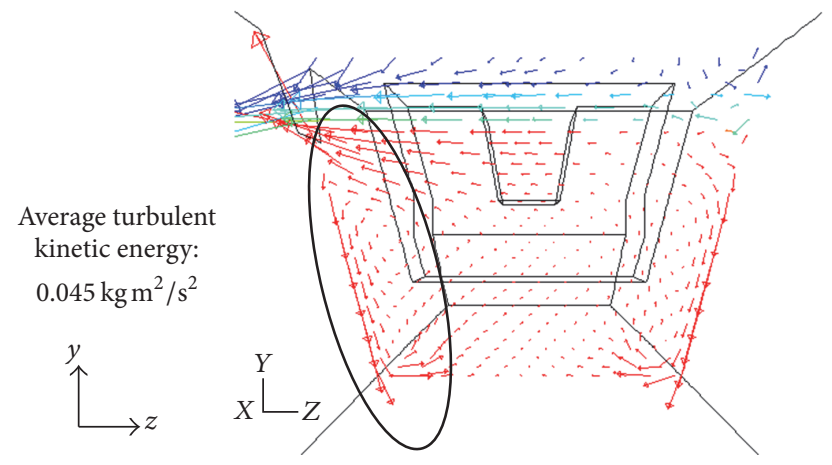

(b)

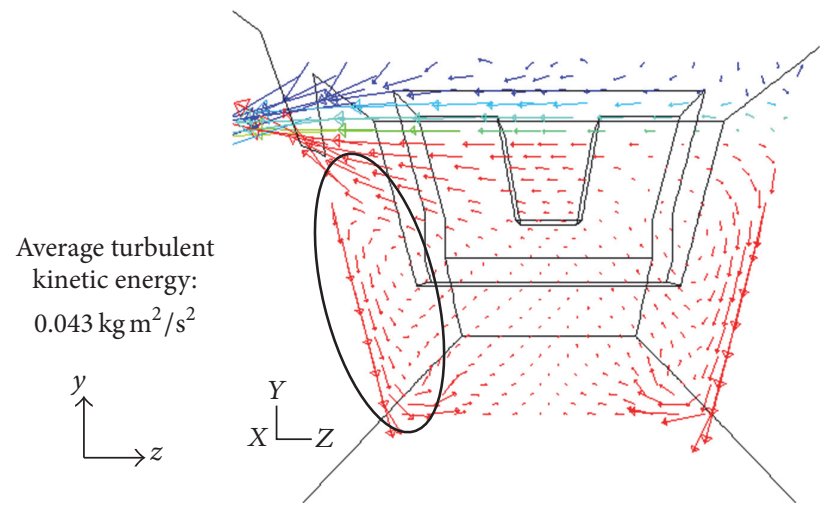

(c)

FIGURE 12: Cross section view of velocity vector field varying with the depth of skimmer to the trough bottom: (a) $0.1 \mathrm{~m}$; (b) $0.2 \mathrm{~m}$; and (c) $0.3 \mathrm{~m}$, in the buffer region of main trough.

\section{Symbols}

$A_{\text {in: }}$ The cross area at the inlet $\left[\mathrm{m}^{2}\right]$

$A_{\text {out }}$ : The cross area at slag port $\left[\mathrm{m}^{2}\right]$

$C_{p \text {,mix }}$ : The mean specific heat $\left[\mathrm{Jkg}^{-1} \mathrm{~K}^{-1}\right]$

$C_{p, q}: \quad$ The specific heat of individual fluid $\left[\mathrm{Jkg}^{-1} \mathrm{~K}^{-1}\right.$ ]

$C_{\mu}: \quad$ An empirical constant specified in the turbulence model (0.09) [-]

$g_{x}: \quad$ The gravity acceleration $\left[\mathrm{ms}^{-2}\right]$

$G_{b}$ : The turbulence kinetic energy for thermal buoyancy $\left[\mathrm{kgm}^{2} \mathrm{~s}^{-2}\right]$

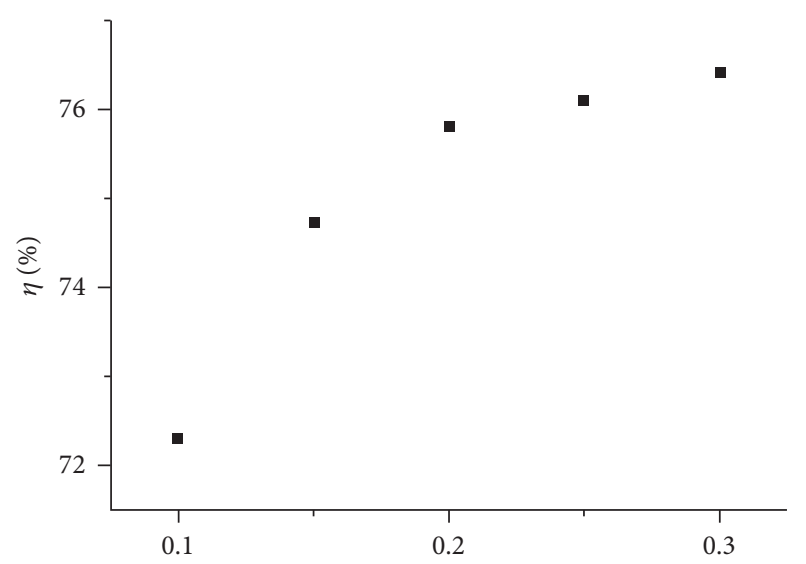

The depth of skimmer to trough bottom of the blast furnace (m)

FIGURE 13: Separation efficiency of the molten iron from the slag as function of the depth of skimmer to the trough bottom of the blast furnace.

$G_{k}: \quad$ The turbulence kinetic energy due to velocity gradient $\left[\mathrm{kgm}^{2} \mathrm{~s}^{-2}\right]$

$h_{h m}: \quad$ The thicknesses of molten iron layers at the initial stage $[\mathrm{m}]$

$h_{H M}: \quad$ The distance from the skimmer bottom to the top of iron dam $[\mathrm{m}]$

$h_{s}$ : The thicknesses of molten slag at the initial stage [m]

$\vec{i}: \quad$ Unit vector in the $x$-direction $[-]$

$\vec{j}: \quad$ Unit vector in the $y$-direction $[-]$

$k: \quad$ The turbulent kinetic energy $\left[\mathrm{kgm}^{2} \mathrm{~s}^{-2}\right]$

$\vec{k}: \quad \quad \quad$ Unit vector in the $z$-direction [-]

$K_{h m}: \quad$ The distance from iron dam to the top of main trough $[\mathrm{m}]$

$K_{s}: \quad$ The depth of slag port [m]

$K_{s y}: \quad$ The depth of skimmer [m]

$\dot{m}_{\text {in }}$ : Mass flow rate of molten iron at the taphole $\left[\mathrm{kgs}^{-1}\right]$

$\dot{m}_{\text {in total }}$ : Total mass flow rate of molten iron at the taphole $\left[\mathrm{kgs}^{-1}\right]$

$\dot{m}_{\text {out }}: \quad$ Mass flow rate of molten iron at the slag port $\left[\mathrm{kgs}^{-1}\right]$

$\dot{m}_{\text {out total }}:$ Total mass flow rate of molten iron at the iron and slag ports $\left[\mathrm{kgs}^{-1}\right]$

$\vec{n}: \quad$ Normal vector $[\mathrm{m}]$

$P: \quad$ Pressure $[\mathrm{Pa}]$

$q: \quad$ Index of fluid phase [-]

$t: \quad$ Time [s]

T: $\quad$ Temperature $[\mathrm{K}]$

$u: \quad$ Velocity in the $x$-direction $\left[\mathrm{ms}^{-1}\right]$

$\vec{u}: \quad$ Velocity vector $\left[\mathrm{ms}^{-1}\right]$

$\vec{u}_{\text {iron }}: \quad$ Velocity of molten iron at the inlet $\left[\mathrm{ms}^{-1}\right]$

$\vec{u}_{\text {slag }}: \quad$ Velocity of molten slag at the inlet $\left[\mathrm{ms}^{-1}\right]$

$\overline{u^{\prime} v^{\prime}}: \quad$ Mean velocity fluctuation $\left[\mathrm{ms}^{-1}\right]$

$v: \quad$ Velocity in the $y$-direction $\left[\mathrm{ms}^{-1}\right]$

$w: \quad$ Velocity in the $z$-direction $\left[\mathrm{ms}^{-1}\right]$ 
$x, y, z:$ Coordinates $[\mathrm{m}]$

$\Delta: \quad$ The criteria defined by equation (14) [-]

$\vec{\nabla}: \quad$ Vector differential operator $\left[\mathrm{m}^{-1}\right]$.

\section{Greek Symbols}

$\alpha: \quad$ The fraction of volume [-]

$\beta$ : Thermal expansion coefficient $\left[\mathrm{K}^{-1}\right]$

$\Phi_{q}$ : Heat conductivity of individual fluid $\left[\mathrm{Wm}^{-1} \mathrm{~K}^{-1}\right]$

$\Phi_{\text {mix }}$ : Mean heat conductivity $\left[\mathrm{Wm}^{-1} \mathrm{~K}^{-1}\right]$

$\eta: \quad$ Separation efficiency [-]

$\rho_{\text {iron }}:$ The density of molten iron $\left[\mathrm{kgm}^{-3}\right]$

$\rho_{\text {mix }}:$ The mean density $\left[\mathrm{kgm}^{-3}\right]$

$\rho_{q}: \quad$ Density of individual fluid $\left[\mathrm{kgm}^{-3}\right]$

$\mu_{\text {eff }}$ : The effective viscosity $\left[\mathrm{kgm}^{-1} \mathrm{~s}^{-1}\right]$

$\mu_{\text {mix }}$ : The mean viscosity $\left[\mathrm{kgm}^{-1} \mathrm{~s}^{-1}\right]$

$\mu_{q}$ : Viscosity of individual fluid $\left[\mathrm{kgm}^{-1} \mathrm{~s}^{-1}\right]$

$\mu_{t}$ : The turbulent viscosity $\left[\mathrm{kgm}^{-1} \mathrm{~s}^{-1}\right]$

$\tau_{w}: \quad$ The wall shear stress [Pa].

\section{Subscripts}

$q$ : Phase number indicating air, slag, and iron, respectively $[-]$.

\section{Competing Interests}

The authors declare that they have no competing interests.

\section{Acknowledgments}

The authors would like to express sincere appreciation to Ministry of Science Technology (MOST: 103-2221-E-005089) and New Materials Research \& Development Department, China Steel Corporation for funding of this study.

\section{References}

[1] T. Letcher, J. Scot, and D. A. Patterson, Chemical Processes for a Sustainable Future, Royal Society of Chemistry, 2014.

[2] M. J. Luomala, T. T. Paanen, M. J. Köäykkä, T. M. J. Fabritus, H. Navla, and J. Härrhhi, "Modelling of fluid in the blast furnace trough," Steel Research, vol. 4, pp. 130-135, 2001.

[3] A. Kumar, S. Ali Khan, S. Biswas, and A. Pal, "Strategic steps towards longer and reliable blast furnace trough campaignTata Steel experience," Ironmaking and Steelmaking, vol. 37, no. 1, pp. 15-20, 2010.

[4] A. E. A. Nogueira, M. B. Mourão, C. Takano, and D. M. dos Santos, "Effect of slag composition on iron nuggets formation from carbon composite pellets," Materials Research, vol. 13, no. 2, pp. 191-195, 2010.

[5] N. I. Fedorova, S. A. Semenova, and Z. R. Ismagilov, "Material composition of fractions with different densities separated from slurry coal," Solid Fuel Chemistry, vol. 47, no. 4, pp. 243-248, 2013.

[6] J. Lasota, "Refractory linings of pig iron transfer ladles," Ceramic Materials, vol. 63, no. 3, pp. 692-695, 2011.
[7] A. S. Semykina, V. I. Shatokha, S. Seetharaman, and O. Y. Gorobets, "Physical simulation of magnetite particle motion in the molten steelmaking slag," Metallurgical and Mining Industry, vol. 3, no. 3, pp. 82-86, 2011.

[8] G. S. V. Kumar, B. S. Murty, and M. Chakraborty, "Settling behaviour of $\mathrm{TiAl}_{3}, \mathrm{TiB}_{2}, \mathrm{TiC}$ and $\mathrm{AlB}_{2}$ particles in liquid $\mathrm{Al}$ during grain refinement," International Journal of Cast Metals Research, vol. 23, no. 4, pp. 193-204, 2010.

[9] R. H. Eric, "Slag properties and design issues pertinent to matte smelting electric furnaces," The Journal of the South African Institute of Mining and Metallurgy, vol. 104, no. 9, pp. 499-510, 2004.

[10] P. Scheller and R. Hagemann, "Model investigations on slag entrainment in continuous casting," Archives of Metallurgy and Materials, vol. 57, no. 1, pp. 283-289, 2012.

[11] S. Saint-Jean, A. Testa, L. V. Madden, and L. Huber, "Relationship between pathogen splash dispersal gradient and Weber number of impacting drops," Agricultural and Forest Meteorology, vol. 141, no. 2-4, pp. 257-262, 2006.

[12] R. K. Thakur, C. Vial, G. Djelveh, and M. Labbafi, "Mixing of complex fluids with flat-bladed impellers: effect of impeller geometry and highly shear-thinning behavior," Chemical Engineering and Processing: Process Intensification, vol. 43, no. 10, pp. 1211-1222, 2004.

[13] A. A. Antonov, M. F. Mar'yasov, and V. V. Khoroshikov, "Design changes to main troughs to reduce loss of pig iron with slag," Metallurgist, vol. 28, no. 3, pp. 85-86, 1984.

[14] N. Fukami, R. Wakamatsu, N. Shinozaki, and K. Wasai, "Wettability between porous $\mathrm{MgAl}_{2} \mathrm{O}_{4}$ substrates and molten iron," Materials Transactions, vol. 50, no. 11, pp. 2552-2556, 2009.

[15] Y. Zhao, G. Chen, and Q. Yuan, "Liquid-liquid two-phase flow patterns in a rectangular MicroChannel," AIChE Journal, vol. 52, no. 12, pp. 4052-4060, 2006.

[16] M. J. Golding, J. A. Neufeld, M. A. Hesse, and H. E. Huppert, "Two-phase gravity currents in porous media," Journal of Fluid Mechanics, vol. 678, pp. 248-270, 2011.

[17] O. Srámek, Y. Ricard, and D. Bercovici, "Simultaneous melting and compaction in deformable two-phase media," Geophysical Journal International, vol. 168, no. 3, pp. 964-972, 2007.

[18] Q. Yuan, B. G. Thomas, and S. P. Vanka, "Study of transient flow and particle transport in continuous steel caster molds: part I. Fluid flow," Metallurgical and Materials Transactions B: Process Metallurgy and Materials Processing Science, vol. 35, no. 4, pp. 685-702, 2004.

[19] S. Feldbauer, J. Harmanand, and A. W. Cramb, "Slag entrainment in continuous casting," CISR Reports, Carnegie Mellon University, 1994.

[20] H. Kim, B. Ozturk, and R. J. Fruehan, "Slag-metal separation in the blast furnace trough," ISIJ International, vol. 38, no. 5, pp. 430-439, 1998.

[21] M. J. Luomala, T. T. Paananen, M. J. Köykkä, T. M. Juhani Fabritius, H. Nevala, and J. J. Härkki, "Modelling of fluid flows in the blast furnace trough," Steel Research, vol. 72, no. 4, pp. 130-135, 2001.

[22] I. Jimbom and A. W. Cramb, "The density of liquid iron-carbon alloys," Ironmaking \& Steelmaking, vol. 15, pp. 55-63, 1993.

[23] H. Efendy, M. Safarudin, and H. Sihombing, "Molten metalslag-refractory reactions during converting process," International Journal of Engineering \& Technology, vol. 10, pp. 40-44, 2010. 
[24] A. Kumar, S. N. Bansal, and R. Chandraker, "Computational modeling of blast furnace cooling stave based on heat transfer analysis," Materials Physics \& Mechanics, vol. 15, pp. 46-56, 2012.

[25] S. I. Karakashev and R. Tsekov, "Electro-marangoni effect in thin liquid films," Langmuir, vol. 27, no. 6, pp. 2265-2270, 2011.

[26] B. G. Thomas, "Modeling of continuous-casting defects related to mold fluid flow," in Proceedings of the Congress on Science \& Technology of Steel making, pp. 847-851, 2005.

[27] R. B. Bird, W. E. Stewart, and E. N. Lightfoot, Transport Phenomena, John Wiley \& Sons, New York, NY, USA, 2007.

[28] M. Owkes and O. Desjardins, "A computational framework for conservative, three-dimensional, unsplit, geometric transport with application to the volume-of-fluid (VOF) method," Journal of Computational Physics, vol. 270, pp. 587-612, 2014.

[29] P. J. Pahl and R. Damrath, Mathematical Foundations of Computational Engineering, Springer, Berlin, Germany, 2001.

[30] A. K. A. Shati, S. G. Blakey, and S. B. M. Beck, "A dimensionless solution to radiation and turbulent natural convection in square and rectangular enclosures," Journal of Engineering Science and Technology, vol. 7, no. 2, pp. 257-279, 2012.

[31] R. Absi, "Analytical solutions for the modeled $k$ equation," Journal of Applied Mechanics, vol. 75, no. 4, 4 pages, 2008.

[32] R. Kuma and A. Dewan, "Assessment of buoyancy-corrected turbulence models for thermal plumes," Engineering Applications of Computational Fluid Mechanics, vol. 7, no. 2, pp. 239249, 2013.

[33] S. Edwards, Fluent Aphasia, Cambridge Studies in Linguistics, Cambridge University Press, Cambridge, UK, 2005.

[34] M. A. Sohail and R. Ullah, "CFD of oscillating airfoil pitch cycle by using PISO algorithm," Engineering and Technology, vol. 60, pp. 1929-1933, 2011.

[35] J. W. Banks and W. D. Henshaw, "Upwind schemes for the wave equation in second-order form," Journal of Computational Physics, vol. 231, no. 17, pp. 5854-5859, 2012. 


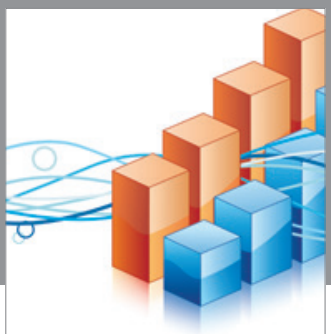

Advances in

Operations Research

vatem alat4

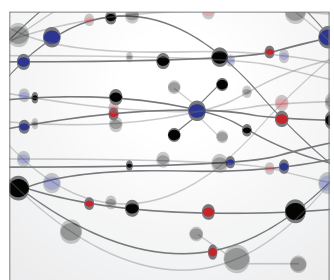

\section{The Scientific} World Journal
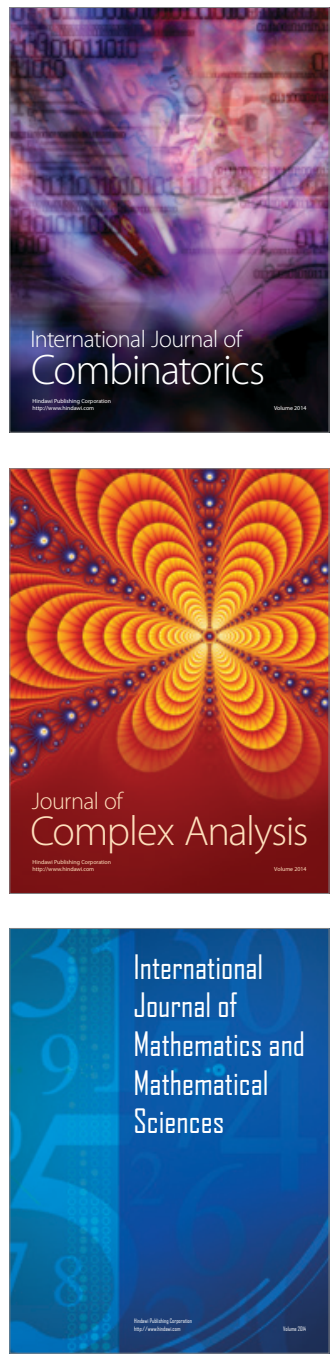
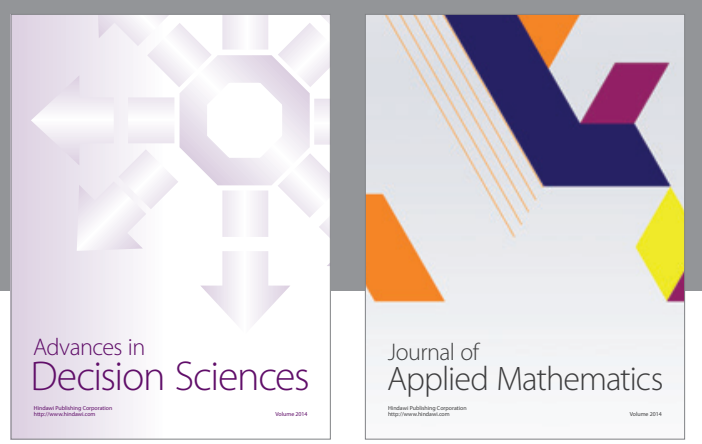

Algebra

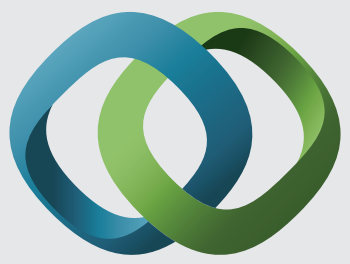

\section{Hindawi}

Submit your manuscripts at

https://www.hindawi.com
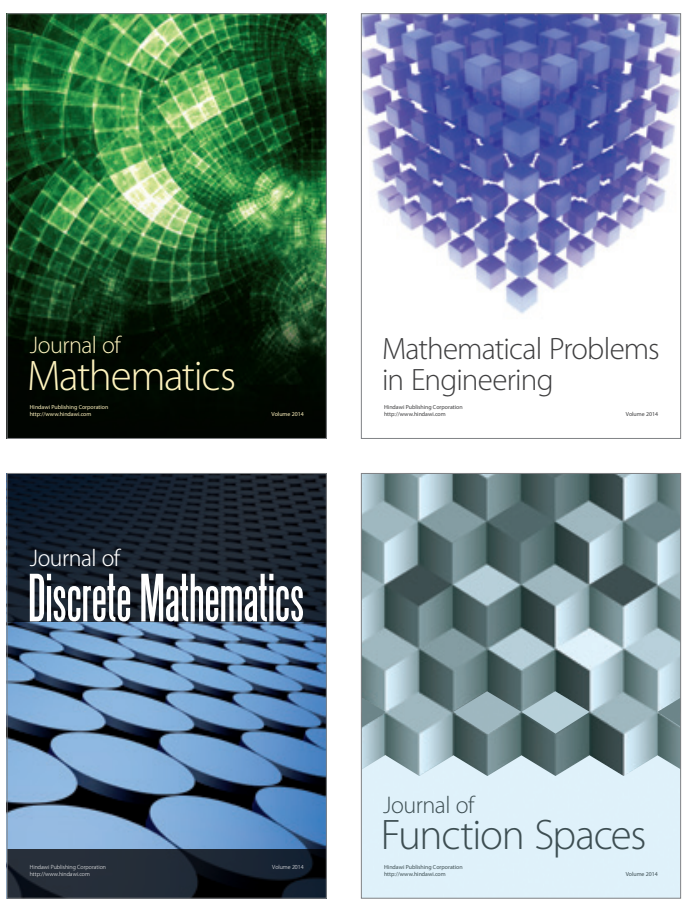

Mathematical Problems in Engineering
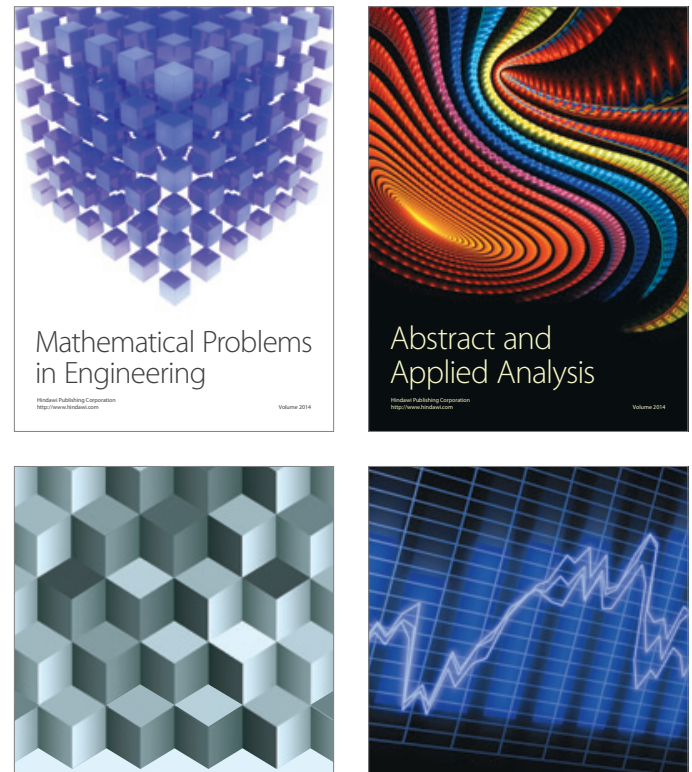

Journal of

Function Spaces

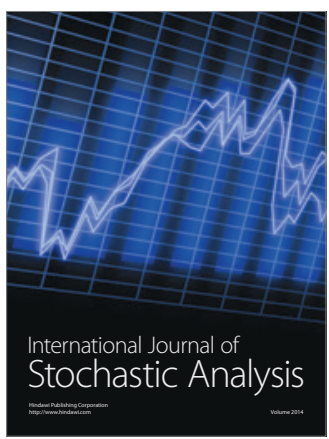

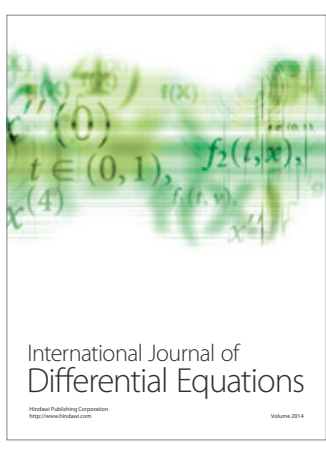
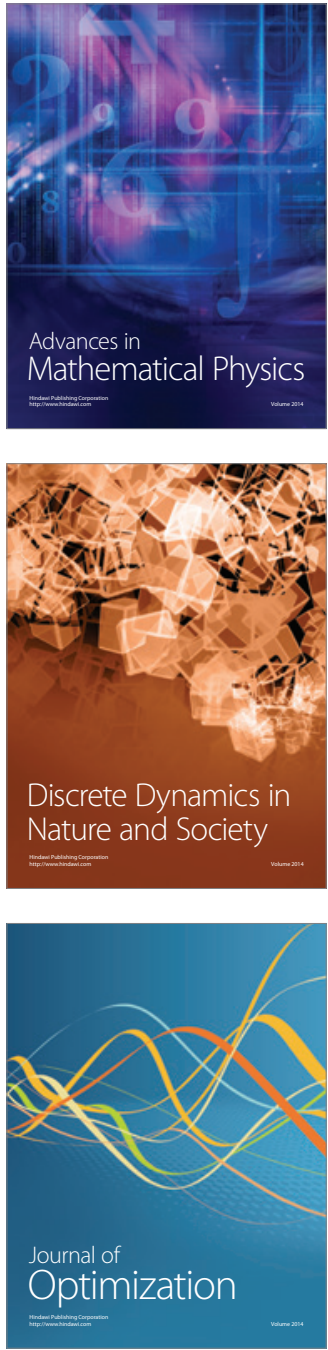